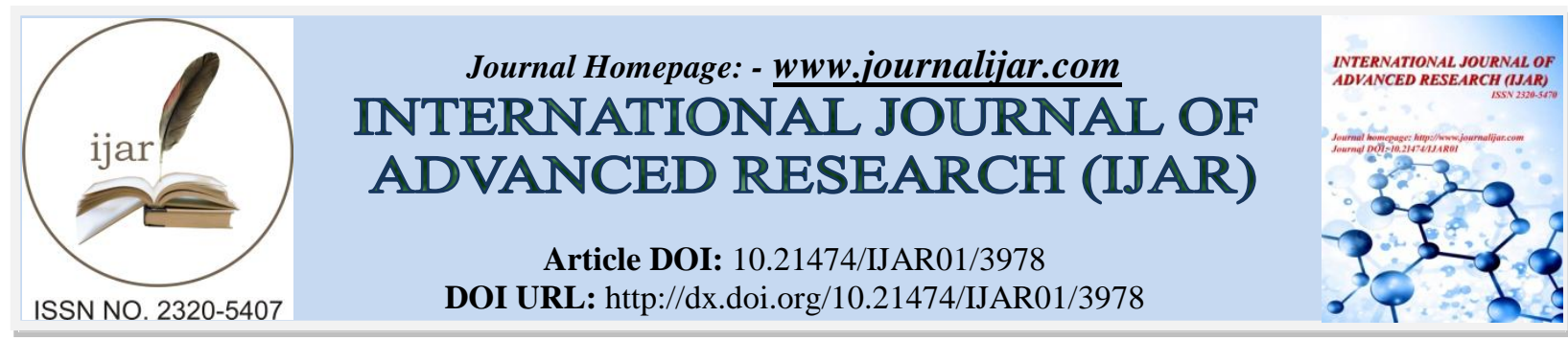

RESEARCH ARTICLE

\title{
BACTERIOLOGICAL AND CLINICAL PROFILE OF COMMUNITY ACQUIRED PNEUMONIA IN A TERTIARY CARE HOSPITAL.
}

\section{Dr. Somnath Bhattacharya ${ }^{1}$, Dr. Saurav Kar ${ }^{2}$, Dr. Suranjan Pal $^{3}$ and Dr. Palash Nandan Dhara ${ }^{4}$.}

1. MBBS (Cal), M.D. (Pulmonary Medicine), Associate Professor, Department of Pulmonary Medicine. R.G.Kar Medical College, Kolkata.

2. MBBS (Cal), DTCD, M.D. (Pulmonary Medicine), Senior Resident, Department of Pulmonary Medicine. R.G.Kar Medical College, Kolkata.

3. MBBS (Cal), M.D. (Microbiology) Demonstrator Cum Clinical Tutor, Department of Microbiology. IPGMER, Kolkata.

4. MBBS (Cal), M.D. (Pulmonary Medicine), Department of Pulmonary Medicine. R.G.Kar Medical College, Kolkata.

\section{Manuscript Info}

Manuscript History

Received: 19 February 2017

Final Accepted: 03 March 2017

Published: April 2017

Key words:-

Community Acquired Pneumonia

(CAP), Sputum Culture, Blood Culture.
Abstract

Context: Community acquired pneumonia (CAP) is still a significant cause of morbidity and mortality throughout the world despite availability of potent antimicrobials.

Aims: The objective of our study was to look into the bacteriological and clinical profile of CAP patients requiring admission in our tertiary care hospital in Kolkata, West-Bengal.

Settings and Design: This was a prospective, observational, cross sectional study comprising of 128 patients admitted in chest ward with CAP.

Methods and material: At the time of admission a detailed history and clinical examination, chest radiography, complete hemogram, glycemic status, renal and liver function tests were done in all patients. Sputum sample was collected for gram staining and bacteriological culture on blood agar and MacConkeys agar media. Two blood samples were sent for culture.

Statistical analysis used: Predesigned and pretested schedule for collection of baseline informations. For statistical analysis multiple logistic regression were performed with SPSS programme version 16 .

Results: Our results showed that mean age was $42.13 \pm 9.8 \mathrm{yrs}$ with male predominance (M:F 2.28:1). The commonest presenting symptom was cough, whereas the commonest clinical sign was tachypnea. Microorganism could be isolated in sputum culture in $75 \%$ of cases, but yield of blood culture was low(9\%). The commonest microorganism isolated was Streptococcus Pneumonia in $41 \%$ cases followed by Pseudomonas in $11 \%$ cases. In diabetic patients, the commonest organism was Streptococcus Pneumonia (28\%), but proportion of Klebsiella species was also high(16\%).

Conclusion: The present study showed that microorganisms can be isolated in significant number of cases of CAP in sputum culture, but the yield of blood culture is low. The microbiological pattern in samples may differ, but knowledge of distribution in certain

Corresponding Author:- Dr. Saurav Kar. 
geographical area is always helpful for initiation of empirical therapy to guide a favourable clinical response.

Copy Right, IJAR, 2017,. All rights reserved.

\section{Introduction:-}

Community acquired pneumonia(CAP) is a common cause of morbidity and mortality throughout the world despite availability of potent antibiotics. It is the sixth leading cause of death in USA. ${ }^{[1]}$ Globally around four million people are affected with CAP and around one-fifth of them required hospitalisation. ${ }^{[2]}$ True incidence of pneumonia in India is difficult to know but it is one of the leading cause of death. ${ }^{[3]}$ The nature of the causative microbiological organism is variable depending upon the age of the patient, presence of structural lung diseases like chronic obstructive lung diseases and bronchiectesis, presence of co-morbidities like diabetes mellitus, renal and hepatic diseases $^{[4]}$ and presence of smoking and alcohol addiction. Identification of the microbiological etiology helps treatment, but in about half of the cases no organism can be found. ${ }^{[1]}$ The etiological microorganism also differs from place to place as shown in two studies from India. ${ }^{[5,6]}$ The knowledge of the predominant organism in a geographic area often helps to start empirical therapy because despite best of efforts it usually takes a few days to identify the causative organism. In our study we have looked for the bacteriological and clinical profile of CAP patients who required admission in a tertiary care hospital in Kolkata,West Bengal.

\section{Subjects and Methods:-}

This study comprised of total 128 patients who were admitted with CAP in chest ward of R.G.Kar Medical College hospital in Kolkata.

Inclusion Criteria:- 1. Age over 18 years

2. CAP was diagnosed by new or progressive pulmonary infiltrates in chest radiograph along with presence of at least any two of the following: fever, cough, purulent sputum production, leucocytosis $\left(\geq 10000 \mathrm{~mm}^{3}\right)$

Exclusion Criteria: Patients having tuberculosis, HIV infection, leukemia, patients receiving immunosuppressive drugs, chest radiographic features suggestive of congestive cardiac failure, lung cancer, pulmonary infarction.

Permission was obtained from Ethical Committee of the institution for the study.

At the time of admission a detailed history was noted and thorough clinical examination was done on each patient. Chest X-ray, complete hemogram, fasting blood glucose, renal and liver function tests were done in all patients. Sputum sample was collected at the time of admission for gram-staining and bacteriological culture on blood agar and MacConkeys agar media. Adequacy of sputum sample was judged by presence of $\geq 25$ polymorphs and $\leq 10$ epithelial cells per low power field. The patients who were unable to expectorate, $3 \%$ hypertonic saline nebulisation was used for induction of sputum. Two samples of blood drawn from different sites were also sent for culture on blood agar and McConkeys agar at the time of admission.

\section{Results:-}

Present study comprised of 128 patients of which $89(70 \%)$ were male and 39(30\%) were female. Mean age was 42.13 \pm 9.8yrs (range 18-79 yrs). Age and sex distribution are shown in table 1. In our study, 35(27\%) patients were smokers and 32 among them were male(36\% of total male). Chronic alcoholism were present in $11(8.5 \%)$ and all were male. The distribution of pre-existing lung diseases and different co-morbid illnesses are shown in table 2.

In our study, the most common presenting symptom was cough in $121(95 \%)$ patients, followed by sputum production in 111(87\%), fever in $103(80 \%)$, pleuritic chest pain in $72(56 \%)$ and hemoptysis in $28(22 \%)$. The common clinical signs on presentation were tachypnea in 103(80\%), tachycardia in $77(60 \%)$, pallor in $16(12 \%)$, cyanosis in 18(14\%) and hypotension in 16(12\%). 29(23\%)cases were complicated by presence of pleural effusion and among them 7(6\%) were empyema.

Hematological and biochemical parameters were abnormal in several cases. 28(22\%) cases had pallor, 113(88\%) had leucocytosis $>10000 \mathrm{~mm} 3,11(9 \%)$ had leucopenia $<4000 \mathrm{~mm} 3,2$ cases had raised creatinine level and 11(9\%) cases had altered raised liver enzymes. 
All 128 cases were subjected to sputum culture but microorganism were grown in 96(75\%) cases. The distribution of different microorganisms are shown in table-3. The distribution of causative microorganism in old age group $(>65 y r s)$, in persons having pre-existing lung diseases and in persons having co-morbid illness are shown in figure-1. Blood culture was sent in all 128 cases but microorganism were found in only 12(9\%) cases. Staphylococcus aureus(5), Pseudomonas aeruginosa(5) and Klebsiella pneumonia(2) were the organisms isolated in blood culture.

Table 1:- Age and sex distribution of CAP patients.

\begin{tabular}{|l|l|l|l|}
\hline Age $($ years $)$ & Total no. $(\mathrm{n}=128)$ & Male $(\mathrm{n}=89)$ & Female $(\mathrm{n}=39)$ \\
\hline $18-29$ & $47(36.71)$ & $29(32.58)$ & $18(46.15)$ \\
\hline $30-49$ & $36(28.12)$ & $23(25.84)$ & $13(33.33)$ \\
\hline $50-65$ & $24(18.75)$ & $20(22.27)$ & $4(10.25)$ \\
\hline$>65$ & $21(16.40)$ & $17(19.10)$ & $4(10.25)$ \\
\hline
\end{tabular}

Table 2:- Distribution of pre-existing lung diseases and different co-morbid illnesses.

\begin{tabular}{|l|l|l|l|l|l|}
\hline & Age $>65$ years & $\begin{array}{l}\text { Pre-existing lung } \\
\text { disease }\end{array}$ & $\begin{array}{l}\text { Diabetes } \\
\text { mellitus }\end{array}$ & Liver disease & Renal disease \\
\hline $\begin{array}{l}\text { Total } \\
(\mathrm{n}=128)\end{array}$ & 48 & 32 & 13 & 2 \\
\hline Male $(\mathrm{n}=89)$ & 21 & 27 & 24 & 13 & 2 \\
\hline Female $(\mathrm{n}=39)$ & 4 & 21 & 8 & 0 & 0 \\
\hline
\end{tabular}

Table 3:- Distribution of bacteriological profile in sputum culture (qualitative).

\begin{tabular}{|c|c|c|c|}
\hline Causative organism & Total no. $(\mathrm{n}=128)$ & Male $(\mathrm{n}=89)$ & Female $(\mathrm{n}=39)$ \\
\hline Streptococcus pneumonia & $53(41.40)$ & $40(44.94)$ & $13(33.33)$ \\
\hline Staphylococcus aureus & $8(6.25)$ & $5(5.61)$ & $3(7.69)$ \\
\hline Pseudomonas aeruginosa & $14(10.93)$ & $10(11.23)$ & $4(10.25)$ \\
\hline Klebsiella pneumonia & $11(8.59)$ & $7(7.86)$ & $4(10.25)$ \\
\hline E.coli & $5(3.90)$ & $3(3.37)$ & $2(5.12)$ \\
\hline Hemophilus inluenzae & $4(3.12)$ & $3(2.34)$ & $1(0.78)$ \\
\hline
\end{tabular}

Figure 1:- Distribution of bacteriological profile in different subgroup.

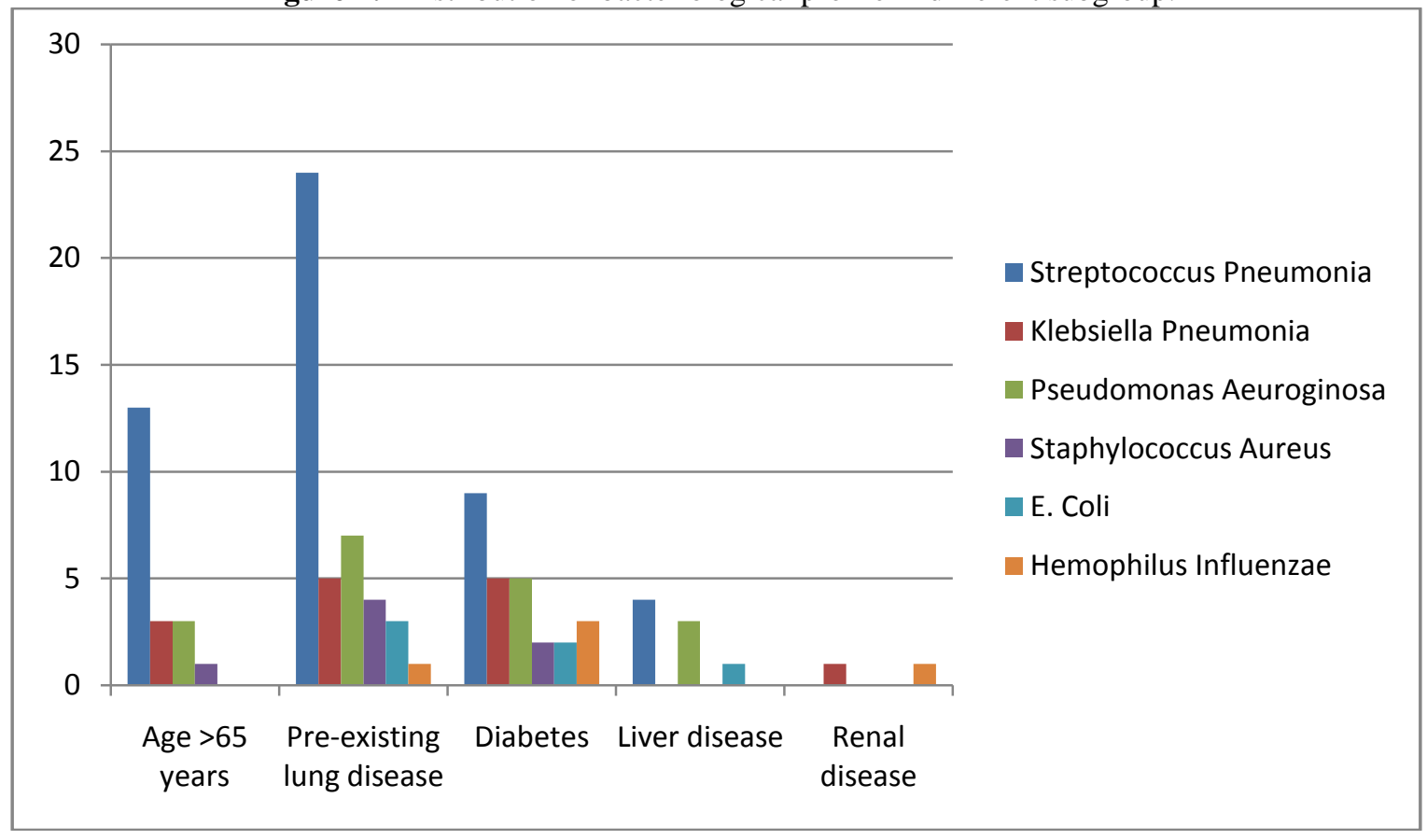




\section{Discussion:-}

In the present study the majority of cases were young as $36 \%$ cases were in between 18 to 29 yrs of age and $65 \%$ were in between 18 to 49 yrs. This may be due to the fact that this age group people were reporting to hospital the most. In most of the previous studies predominant number of patients were older ( $>50 \mathrm{yrs}){ }^{[\mathbf{8 , 1 1}]}$ Most of our patients presented with cough $(95 \%)$ and fever which are same as found in previous studies. ${ }^{[6,11,14]} 37.5 \%$ of our cases had co-existing lung diseases. In our study microorganisms were found in $75 \%$ cases in sputum culture, whereas only in $9 \%$ cases microorganisms were grown in both sputum and blood cultures. Rate of isolation of bacteria from sputum culture in most of the previous Indian studies varied from $26 \%$ to $47 \% .^{[\mathbf{6 , 7 , 9 , 1 0 , 1 1 , 1 5 ]}}$ But some Indian studies reported higher rate of culture positivity like $63 \%$ cases. ${ }^{[13]}$ Addition of invasive procedures and serology increase the yield (75.7\% cases) as shown in one study from Bansal et.al. ${ }^{[6]}$ Application of newer diagnostic tools like real time PCR increase the yield further upto $89 \%$ as reported in one study from Sweden. ${ }^{[\mathbf{1 6}]}$ But facilities for serological tests and other invasive new diagnostic tests are not available in most of the hospitals in India like ours setting. In our study we could isolate microorganism in $75 \%$ cases by sending sputum before starting antibiotics. Yield from blood culture was low in our $\operatorname{study}(9 \%)$ which closely matches with that of other studies. ${ }^{[6,11,17]}$ The commonest microorganism isolated in sputum culture were Streptococcus Pneumoniae(41\%). S.Pneumoniae is known as the commonest cause of CAP as corroborated in several studies from different countries in last several decades. ${ }^{[3,17,18,19]}$

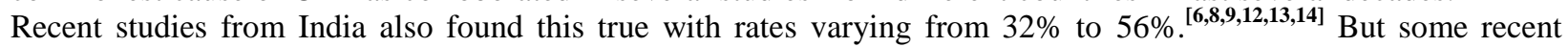
studies from India shows that incidence of Klebsiella Pneumoniae as causative bacteria of CAP has increased (14\%$22 \%$ ) and it became $2^{\text {nd }}$ commonest cause of CAP. ${ }^{[6,8,9]}$ In our study we found occurrence of klebsiella around $9 \%$ and comes $3^{\text {rd }}$ after Pseudomonas $(11 \%)$. One study from Srinagar found Psudomonas as commonest cause of CAP ${ }^{[5]}$ This rising trend of Klebsiella and Pseudomonas associated pneumonia may be due to increased incidence of diabetes melitus in India. In present study we found $25 \%$ cases have diabetes mellitus and though S.Pneumoniae was found to be commonest $(28 \%)$ among them, yet Klebsiella and Pseudomonas both were found in $15 \%$ each. Gram negative bacilli were found in $26.5 \%$ cases overall but in diabetic and in cases having co-existing lung diseases, gram negative bacilli were found in $47 \%$ and $33 \%$ respectively. Previous two studies from India found Klebsiella in nearly half the cases of CAP with diabetes mellitus. ${ }^{[12,13]}$ Diabetic patients are immunosuppressed and their pulmonary defence machanisms are also altered. This makes them more prone to klebsiella and other gram negative infection.

\section{Conclusion:-}

The present study showed that microorganism can be isolated in sputum culture in a significant number of cases with CAP but the yield of blood culture is low. This study also showed that the commonest etiological agent of CAP was Streptococcus Pneumoniae though the incidence of Klebsiella Pneumoniae was also high and this is particularly true in cases with diabetes mellitus. The microbiological pattern in samples may differ, but knowledge of distribution in a certain geographical area is always helpful for initiation of empirical therapy to guide a favourable clinical response.

\section{References:-}

1. Fang GD, Fine M, Orloff $\mathbf{J}$ et al. New and emerging etiologies for community acquired pneumonia with implications for therapy: A prospective multicentric study of 359 cases. Medicine (Baltimore) 1990;69:307-16.

2. Garibaldi RA. Epidemiology of community acquired respiratory tract infections in adults: Incidence, etiology and impact. Am J Med 1985;78:325-75.

3. Kulpati DDS, Khastagir T. Reappraisal of pneumonias. J Assoc Physicians India 1988;36:660-64.

4. Guidelines for the initial management of adults with community acquired pneumonia. Diagnosis, assesement of severity and initial antimicrobial therapy. Am Rev Respir Dis 1993;148:1418-26.

5. Basir Ahmed Shah et al. Bacteriological and clinical profile of community acquired pneumonia in hospitalized patients. Lung India 2010;27(2):54-57.

6. Bansal S, Kashyap S, Pal LS, Goel A. Clinical and bacteriological profile of community acquire pneumonia in Shimla, Himachal Pradesh. Indian J Chest Dis \& Allied Sci 2004;46:17-22.

7. Oberoi A, Agarwal A. Bacteriological profile, serology and antibiotic sensitivity pattern of microorganisms from community acquired pneumonia. J K Sci 2006;8:79-82.

8. Menon RU, George AP, Menon U. Etiology and antimicrobial sensitivity of organism causing community acquired pneumonia: A single hospital study: J of Family Medicine and Primary Care 2013;2(2):244-9.

9. Puspakumari RS, Vipula VA, Jain S. Clinical, radiological and bacteriological profile of patients with community acquired pneumonia: International Archives of Integrated Medicine 2016;3(6):59-64. 
10. Chauhan JB, Boringer GB, Shah KV. Clinical and bacteriological profile of hospitalised community acquired pneumonia SEAJCRR 2014;3(1):619-27.

11. Giriraj B, Manthale D. Clinico-microbiological profile of community acquired pneumonia in a tertiary care hospital. Journal of Biomedical and Pharmaceutical research 2015;4(4):65-68.

12. Kejriwal A, Shenoi AS, Pusukusu R, Sebastian C, Bhuta K. A Clinical, bacteriological and radiological profile of community acquired pneumonia in Navi Mumbai, India:IOSR-JDMS 2015;14(9):58-61.

13. Dharmadhikari V, Joseph T, Kulkarni A. Bacteriological and clinical profile of community acquired pneumonia in hospitalised patients. International journal of Pharma and Biosciences 2013;4(2):695-702.

14. Jain SK, Jain S, Trikha S. Study of clinical, radiological and bacteriological profile of community acquired pneumonia in hospitalised patients of Gajra Raja Medical College, Gwalior, Central India. International Journal of Scientific Study 2014;2(6):96-100.

15. Mythri S, Natarajan HV. Bacteriological profile of community acquired pneumonia. IOSR Journal of Dental and Meical Sciences. 2013;12(2):6-9.

16. Johansson N, Kalin M, Tiveljung-Lindell A, Giske GC, Hedlund J. Etiology of Community-Acquired Pneumonia: Increased Microbiological Yield with New Diagnostic Methods. Clinical Infectious Diseases. 2010;50(2):202-9.

17. Humphery JH, Joules H. Pneumonia in north. Thorax 1948;3:112-121.

18. Bath JC, Boisard GP, Caldre MA, Wood SC, Rowansky MJ, Chanock RM. Pneumonia in hospital practice in Edinburgh. Br. J. Dis. Chest 1964;58:1-16.

19. Dorff GJ, Rytel MW, Farmer SG, Scanlon G. Etiologies and characteristic features of pneumonia in a municipal hospital. Am J Med Sci 1973;266:349-58.

\section{Acknowledgement:-}

NIL 